\title{
Physical fitness and quality of life in adolescents with asthma and fixed airflow obstruction
}

\author{
Andrey Sousa ${ }^{1}$, Anna Lúcia Cabral ${ }^{2}$, Ronaldo Silva ${ }^{3}$, José Grindler ${ }^{4}$, Alfredo Fonseca ${ }^{4}$, \\ Milton Martins ${ }^{4}$, and Celso Carvalho ${ }^{5}$ \\ ${ }^{1}$ University of São Paulo \\ ${ }^{2}$ Darcy Vargas Children's Hospital \\ ${ }^{3}$ Universidade Brasil \\ ${ }^{4}$ School of Medicine, University of Sao Paulo \\ ${ }^{5}$ School of Medicine, University of Sao Paulo
}

July 7,2020

\begin{abstract}
Asthma is a disease characterized by reversible bronchoconstriction, but some subjects develop fixed airflow obstruction (FAO). Subjects with FAO present more asthma symptoms and may have increased sedentary behavior; however, the effect of FAO on aerobic fitness and physical activity levels (PAL) remains poorly understood. Aim: To compare adolescents with asthma and FAO and adolescents with asthma without FAO in terms of aerobic fitness, PAL, muscle strength, and health-related quality of life (HRQoL). Methods: This cross-sectional study included adolescents with asthma, both sexes, and aged 12 to 18 years. They were divided into 2 groups: FAO and non-FAO groups. The adolescents were diagnosed with asthma in accordance with the Global Initiative for Asthma guidelines and underwent optimal pharmacological treatment for at least 12 months. FAO was diagnosed when FEV1/FVC ratio was below the lower limit of normal range after optimal treatment. Aerobic fitness, PAL, peripheral and respiratory muscle strength, and HRQoL were evaluated. Results: No significant differences were observed between FAO and non-FAO groups regarding the peak oxygen uptake (34.6 $\pm 8.5 \mathrm{vs} .36 .0 \pm 8.4 \mathrm{mLO} 2 / \mathrm{min} / \mathrm{kg})$, sedentary time ( $578 \pm 126$ vs. $563 \pm 90 \mathrm{~min} /$ day), upper limb muscle strength ( $29.1 \pm 5.9$ vs. $28.1 \pm 5.7 \mathrm{kgf})$, lower limb muscle strength (42.8 \pm 8.6 vs. $47.6 \pm 9.6 \mathrm{kgf})$, or HRQoL ( $5.1 \pm 1.3$ vs. $4.7 \pm 1.4$ score) $(\mathrm{p}>0.05)$. However, the FAO group exhibited a higher maximal expiratory pressure than did the non-FAO group ( $111.5 \pm 15.5$ vs. $101.5 \pm 15.0 \mathrm{cmH} 2 \mathrm{O}$, respectively). Conclusion: Our results suggest that FAO does not impair aerobic fitness, PAL, peripheral muscle strength, or HRQoL in adolescents with asthma. Furthermore, adolescents with asthma were physically deconditioned.
\end{abstract}

\section{Introduction}

Asthma is a chronic disease characterized by airway inflammation and diagnosed if a subject has a history of respiratory symptoms such as wheezing, shortness of breath, chest tightness, and coughing as well as variable airflow obstruction (1). Airflow obstruction can often be reversed either spontaneously or with pharmacological treatment (1). However, approximately $10 \%$ of infant subjects with asthma in a previous study exhibited an expiratory airflow limitation that was not completely reversible, despite optimal treatment being provided (2); this condition is known as fixed airflow obstruction (FAO) (3).

FAO is diagnosed when a subjects' ratio of the forced expiratory volume in the $1^{\text {st }}$ second $\left(\mathrm{FEV}_{1}\right)$ to the forced vital capacity $(\mathrm{FVC})\left(\mathrm{FEV}_{1} / \mathrm{FVC}\right)$ is below the lower limit of the normal range (LLN) after optimal treatment (3). The development of FAO has been explained by a type of pathological airway remodeling that leads to structural changes in the airway and airflow restrictions (4). The risk factors for FAO are multifactorial and differ between adults and children $(2,5)$. The main risk factors for FAO in adults include 
a subjects' sex, his or her smoking habits, the presence of rhinitis, atopy, and eosinophil inflammation; and the amount of fractional exhaled nitric oxide (5). In children and adolescents, the risk factors are related to asthma severity and the frequency of exacerbations (2).

Previous studies have reported that subjects with FAO exhibit higher asthma hospitalization rates and more severe symptoms such as dyspnea, wheezing, and chest tightness than do their non-FAO peers $(2,4)$. The fear of feeling asthma symptoms could inhibit many subjects from taking part in regular physical activity due to exercise-induced bronchoconstriction (6). The current guidelines encourage subjects with asthma to engage in regular physical activity (1). An increase in a subject physical activity level (PAL) improves his or her aerobic fitness and health-related quality of life (HRQoL) and reduces the need for inhaled corticosteroids, asthma exacerbations, and dyspnea symptoms (7). In addition, adolescents with asthma who remain physically active exhibit a slower annual decline in the $\mathrm{FEV}_{1}$ and $\mathrm{FEV}_{1} / \mathrm{FVC}$ ratio values than do those who are physically inactive (8). Although the benefits of regular physical activity are well known, adults with asthma and FAO are physically inactive and exhibit low levels of aerobic fitness $(8,9)$; however, the effects of FAO in adolescents with asthma remain poorly known.

In the present study, we hypothesized that adolescents with asthma and FAO have lower levels of aerobic fitness, PAL, muscle strength, and HRQoL than do their peers with asthma but without FAO. Our study aimed to compare adolescents with FAO and their non-FAO peers in terms of aerobic fitness, PAL, muscle strength, and HRQoL.

\section{Methods}

\section{Subjects}

This is a cross-sectional study that was conducted in adolescent outpatients with asthma who were recruited from a tertiary university hospital. Asthma was diagnosed in accordance with the Global Initiative for Asthma (GINA) guidelines (1). The inclusion criteria were having undergone medical treatment for at least 12 months according to GINA guidelines (1), being between 12 and 18 years old, and having clinically stable disease (no hospitalizations, emergency care visits, or medication changes in the last 30 days). There were no restrictions regarding sex. The exclusion criteria were the presence of any other pulmonary diseases or cardiovascular, neuromuscular, or neurological diseases. The adolescents were divided into two groups: asthma with FAO (FAO group) and asthma without FAO (non-FAO group) groups. The non-FAO group included outpatients under optimal medical treatment in the same hospital who were recruited using the frequency matching method (10) based on sex, age, and body mass index to avoid bias in the comparisons. Adolescents were included in the non-FAO group in small groups of five. Then, every time that five adolescents were included in the FAO group, the subsequent five subjects were included in the non-FAO group until the total sample size was reached.

The Hospital Research Ethics Committee approved the study, and written informed consent was obtained from the adolescents' caregivers. The costs of transport for all adolescents and their caregivers were covered by the researchers to avoid dropouts. No financial compensation was offered to participate in the study.

\section{Study design}

\section{Protocol}

The adolescents were recruited during a regular medical visit, and they were assessed over two days with a one-week interval. On the first day, the adolescents performed muscle strength assessment tests, completed the HRQoL questionnaire, and received a triaxial accelerometer to wear on their waist for seven days. On the second visit, the adolescents returned the accelerometer and performed a maximal cardiopulmonary exercise test (CPET). This study was conducted between August 2018 and March 2019. Blinded assessors to the group allocation performed all the assessments.

Assessment

Fixed airflow obstruction (FAO) 
Fixed airflow obstruction was defined as the ratio of the forced expiratory volume in the first second to the forced vital capacity $\left(\mathrm{FEV}_{1} / \mathrm{FVC}\right)$ being persistently below the lower limit of normal range (LLN), according to reference equations, even after the use of a postbronchodilator (BD) (3). For adolescents with $\mathrm{FEV}_{1} / \mathrm{FVC}$ ratios lower than the LLN persistently on the two consecutive visits, oral corticosteroids (OC) were prescribed for seven consecutive days (the OC dose ranged from 1 to 2 milligrams (mg) per kg of body weight, up to a maximum dose of $40 \mathrm{mg} /$ day) (1). After seven days of OC treatment, the adolescents returned to the hospital and underwent a new spirometry test. The presence of FAO was noted if the $\mathrm{FEV}_{1} / \mathrm{FVC}$ ratio remained lower than the LLN (3).

\section{Lung function}

The lung function test was evaluated by a spirometer (Koko DigiDoser, Louisville, KY, USA) coupled with a microcomputer. The technical procedure, eligibility criteria, and reproducibility were established in accordance with the American Thorax Society and European Respiratory Society recommendations (11). The following variables were assessed: $\mathrm{FEV}_{1}, \mathrm{FVC}$, and the $\mathrm{FEV}_{1} / \mathrm{FVC}$ ratio. Spirometry was performed before and after $400 \mu \mathrm{g}$ of salbutamol inhaled with an interval of 10 to 15 minutes to evaluate the BD response (11). A positive BD response was considered if a post-BD increase in $\mathrm{FEV}_{1}$ of $>12 \%$ was predicted from the pre-BD value (11). Values were compared with the values predicted based on data from a Brazilian population, and the LLN was evaluated by a program provided by the Global Lung Initiative (11).

\section{Asthma control}

The Asthma Control Test (ACT), validated for Brazilian Portuguese use, was used to assess the level of asthma control (12). The ACT has five questions regarding activity limitation, shortness of breath, and nighttime symptoms experienced over the last four weeks. Each question has five response options ranging from 1 (worst) to 5 (best). The ACT scores range from 0 (totally uncontrolled asthma) to 25 (totally controlled asthma), and scores [?]20 indicate controlled asthma (12).

Anthropometric data and body mass index (BMI)

BMI was calculated by dividing the subjects' weight in kilograms by their height in square meters $\left(\mathrm{kg} / \mathrm{m}^{2}\right)$ (13). The weight status categories were underweight $\left(<5^{\text {th }}\right)$, normal weight $\left(5^{\text {th }}\right.$ to $\left.<85^{\text {th }}\right)$, overweight $\left(85^{\text {th }}\right.$ to $\left.<95^{\text {th }}\right)$, and obese $\left([?] 95^{\text {th }}\right)$.

Health-related quality of life (HRQoL)

HRQoL was assessed using the Pediatric Asthma Quality of Life Questionnaire (PAQLQ), which includes three domains: activity limitations, symptoms, and emotional function (14). The PAQLQ consists of 23 items rated on a 7-point scale (from 1 to 7), and a higher score indicates a better quality of life (14).

Peripheral muscle strength

For upper and lower limb muscle strength, handgrip strength was measured using a hand dynamometer (Jamar hydraulic, Lafayette, IN, USA), and quadriceps strength were measured using a load cell (EMG System, SP, Brazil). In both assessments, the dominant limbs were used, and all adolescents were asked to sustain maximum force for 5 seconds with maximal verbal encouragement during the test. A minimum of three and a maximum of five trials were performed for each test. The interval between measurements was approximately $1 \mathrm{~min}$, and the best value from three acceptable trials presenting a variation $<10 \%$ were considered. The isometric force is expressed in kilogram-force (kgf) and the percentage of the predicted values. The predicted values were obtained from a Brazil population and stratified by sex, age, and weight (15).

\section{Respiratory muscle strength}

Respiratory muscle strength was assessed by measuring the maximal inspiratory (MIP) and expiratory pressures (MEP). The test was performed using a digital manovacuometer (MVD 300-U, Globalmed, RS, Brazil). The device was connected to a tube coupled to a sterilized filter that was attached to a mouthpiece. 
The assessments were performed in a seated position while the subject wore a nose clip. The MIP was assessed after maximal expiration near the residual volume, while the MEP was assessed after maximal inspiration near the total lung capacity (16). Both measurements were performed with maximum effort and sustained for at least 1 second. The number of repetitions, interval time, and best value from the acceptable trials were used for analysis, as in the assessment of peripheral muscle strength. The respiratory muscle strength values are expressed in $\mathrm{cmH}_{2} \mathrm{O}$ and the percentage of the predicted values. The predicted values were obtained from a Brazil population and stratified by sex, age, height, and weight (17).

Physical activity level (PAL)

PAL was objectively quantified using a movement sensor (ActiGraph GT3X; ActiGraph, Pensacola, FL, USA). All units were initialized via a computer interface, and data were collected in 15-sec epochs in all three dimensions using specific software (ActiLife 6.9.5 Firmware version). Each adolescent was instructed to wear the movement sensor on the hip (non-dominant side) using an elastic belt for seven consecutive days. The data are presented as the average number of steps per day and the time spent performing moderate-tovigorous physical activity (MVPA, min* $\mathrm{d}^{-1}$ ), performing light-intensity physical activity, and sitting (18). Adolescents were considered successfully monitored when they used the accelerometer for at least four days for more than 10 hours per day.

\section{Cardiopulmonary exercise test (CPET)}

The CPET was performed using the Vyntus CPX (Carefusion, Germany) linked to a gas analysis system $\left(\mathrm{CardiO}_{2}\right.$ System; Medical Graphics Corporation, MN, USA). The adolescents performed a ramp-symptomlimited CPET consisting of 2 minutes ( $\mathrm{min}$ ) of rest, 3 min of warm-up (unloaded pedaling), and an incremental work period $(15 \mathrm{~W} / \mathrm{min}$ for height $<150 \mathrm{~cm}$ and $20 \mathrm{~W} / \mathrm{min}$ for height [?] $150 \mathrm{~cm})(7)$. During the test, the adolescents were instructed to continue pedaling at $60 \mathrm{rpm}$. The test was set to last from 8 to 12 minutes until $90 \%$ of the maximal heart rate (HR) predicted was reached, and 1.10 of the respiratory exchange rate (RER) was considered available (7). Oxygen saturation $\left(\mathrm{SpO}_{2}\right)$ was measured via pulse oximetry (Onyx, model 9500; Nonin, Plymouth, MN), and the electrocardiography signals (Welch Allyn CardioPerfect, Inc., $\mathrm{NY}$ ) were monitored continuously during the tests. The following variables were recorded: power, peak oxygen uptake $\left(\mathrm{VO}_{2}\right.$ peak), minute ventilation (VE), carbon dioxide production $\left(\mathrm{VCO}_{2}\right)$, RER, and $\mathrm{HR}$. Additionally, blood pressure, the Borg score for leg discomfort, and severity of dyspnea were measured at rest and every 2 min during the test until the end of the test (19). Males and females were considered to have aerobic fitness when they reached $\mathrm{VO}_{2}$ peak [?] 43.4 and [?] $35.6 \mathrm{ml} / \mathrm{kg} / \mathrm{min}$, respectively. If these thresholds were not met, they were considered to have low aerobic fitness (20). The tests were performed in accordance with the American Thoracic Society recommendations. The predicted CPET values were calculated for a Brazilian population (21).

\section{Statistical analysis}

A sample size of 20 adolescents per group was estimated to be needed to detect a difference of $6 \mathrm{ml} / \mathrm{kg} / \mathrm{min}$ with a standard deviation of $6 \mathrm{ml} / \mathrm{kg} / \mathrm{min}$ in the $\mathrm{VO}_{2}$ peak (22). The final sample size was 22 adolescents per group, assuming a loss of up to $10 \%$. The sample size was calculated to provide $80 \%$ power and an alpha level of 0.05 . The normality of the data was evaluated using the Kolmogorov-Smirnov test. The between-group comparisons of the categorical variables and the analysis of the differences in the proportions of adolescents across groups were performed using the chi-square test or Fisher's test. For the between-group comparisons of the continuous variables, the t-test or Mann-Whitney test was used. The data were analyzed using the Statistical Package for Social Science (SPSS) software, version 22.0 (Chicago, IL, USA).

\section{Results}

\section{Adolescents' characteristics}

A total of 44 adolescents were screened; two terminated their participation in the study, and one experienced exacerbated symptoms before the $2^{\text {nd }}$ visit (Figure 1 ). Most of the adolescents were male and had a normal weight, controlled asthma (ACT[?]20), early-onset asthma, and atopic conditions (Table 1). The adolescents 
in the FAO group reported more previous asthma hospitalizations, more cases of early-onset asthma, and more cases of atopic conditions. Besides, they presented poorer lung function $\left(\mathrm{FEV}_{1}\right.$ and $\mathrm{FEV}_{1} / \mathrm{FVC}$ ratio), and a poorer $\mathrm{BD}$ response than did the non-FAO group $(\mathrm{p}<0.05$, Table 1$)$. On the other hand, no significant differences were observed between FAO and non-FAO groups in terms of sex, BMI, inhaled corticosteroid dose, ACT score, blood eosinophils, and FVC $\%$ of the predicted value ( $\mathrm{p}>0.05$, Table 1 ).

- Insert Figure 1 near here -

- Insert Table 1 near here -

Aerobic fitness

Most adolescents in both the FAO and non-FAO groups had low aerobic fitness, with proportions of $85 \%$ and $76 \%$, respectively $(\mathrm{p}>0.05)$. No significant differences were observed between groups in the $\mathrm{VO}_{2}$ peak, minute ventilation, and oxygen pulse recorded during the CPET ( $>0.05$, Table 2). During maximal exercise, ventilation was not considered a limiting factor; however, cardiac function was near the maximal limit (Table 2 ). Peripheral muscle fatigue was more severe than was dyspnea perception, and all adolescents requested to stop the CPET due to lower limb fatigue $(\mathrm{p}<0.05$; Table 2).

- Insert Table 2 near here -

Physical activity levels

The FAO and non-FAO groups spent most of their time performing sedentary behavior $(72.9 \%$ and $73.4 \%$, respectively; $\mathrm{p}>0.05)$. No significant differences in the number of steps per day, sedentary time, or time performing light or moderate-to-vigorous physical activity were observed between the FAO and non-FAO groups ( $>0.05$, Table 3$)$.

\section{Peripheral and respiratory muscle strength}

The inspiratory, handgrip, and quadriceps femoral muscle strength values were similar between the FAO and non-FAO groups ( $\mathrm{p}>0.05$; Table 3$)$. On the other hand, the expiratory muscle strength values were higher in the FAO group than in the non-FAO group $(\mathrm{p}<0.05$; Table 3$)$.

- Insert Table 3 near here -

Health-related quality of life

The FAO and non-FAO groups presented no significant differences in the total PAQLQ score (respectively, $5.1 \pm 1.3$ vs. $4.7 \pm 1.4$ score; $\mathrm{p}>0.05$ ) or in the scores for the three domains: physical activity (respectively, $5.2 \pm 1.1$ vs. $4.8 \pm 1.2$ score; $\mathrm{p}>0.05$ ); symptoms (respectively, $4.9 \pm 1.3$ vs. $4.5 \pm 1.3$ score; $\mathrm{p}>0.05$ ); emotions (respectively, $5.1 \pm 1.5$ vs. $4.7 \pm 1.6$ score; $\mathrm{p}>0.05$ ).

\section{Discussion}

Our results showed that adolescents with FAO and non-FAO adolescents presented similar aerobic fitness, PAL, peripheral muscle strength, and HRQoL results. However, the adolescents in the FAO group presented higher values of expiratory muscle strength than did the non-FAO group. This study also showed that most adolescents with asthma are physically deconditioned and sedentary, regardless of whether the condition was clinically controlled, and FAO was present.

Aerobic fitness and PAL in children and adolescents with asthma have been studied over the last two decades (23-25), and the association between PAL and lung function remains poorly understood $(26,27)$. Loponen et al. (2018) showed that a low PAL was associated with a faster decline in lung function in adults with asthma (8). However, no studies have evaluated the association between PAL and the decline in lung function in children and adolescents with asthma. Contrary to our hypothesis, the present study showed that the FAO and non-FAO adolescents have a similar PAL. Two hypotheses can explain our findings. First, both groups had controlled asthma, and this hypothesis is supported by previous studies showing that subjects with controlled asthma experience fewer asthma symptoms and therefore have a higher PAL than do subjects 
with uncontrolled asthma (28). Second, both groups exhibited a long period of sedentary behavior and a very short period of moderate-to-vigorous physical activity (MVPA).

In our study, most adolescents in the FAO and non-FAO groups presented reduced levels of aerobic fitness, as evaluated by the CPET. All adolescents terminated the CPET due to fatigue in the lower limbs, and they also demonstrated cardiac limitations (reduced cardiac reserve). These results corroborate those in previous studies in either children or adolescents with asthma and those without asthma $(7,21,22)$. Taken together, these results suggest that physical deconditioning, rather than asthma or FAO, is the major cause of interruption during maximal exercise. The reduced levels of aerobic fitness observed in our study may be explained by the reduced MVPA levels; however, the opposite result should be observed if the adolescents participate in a physical training program (29).

Children and adolescents with asthma and their nonasthmatic peers have been shown to have similar levels of respiratory muscle strength (30). On the other hand, children and adolescents with severe asthma have reduced maximal inspiratory pressure (MIP) compared to those with nonsevere asthma (31). This difference probably occurs because airway obstruction leads to static hyperinflation and places the respiratory muscle at a mechanical disadvantage (32). Interestingly, we observed that adolescents with FAO exhibit a higher maximal expiratory pressure (MEP) than do non-FAO adolescents. This finding can be explained by the fact that the lower the airway caliber is, the greater the respiratory requirement for exhaling air from the lungs (32).

Several studies have evaluated upper and lower peripheral muscle strength in children and adolescents with asthma $(22,33,34)$, and most of them did not observe differences between subjects with asthma and their nonasthmatic peers $(22,33)$. Our results showed that the upper and lower limb muscle strength values were similar between the FAO and non-FAO groups. In contrast, Lattorre-Romám et al. (2013) demonstrated different handgrip strength results in subjects with asthma. The authors reported that subjects with a lower $\mathrm{FEV}_{1}$ also had poorer handgrip strength (34). The discrepancy between the results presented by LattorreRomám et al. (2013) and our results may have occurred because Lattorre-Romám et al. (2013) evaluated adolescents with asthma of steps 1 to 5 , while we assessed adolescents with asthma of steps 3 to 5 (mostly severe asthma). Interestingly, in our study, both groups exhibited reduced muscle strength in the upper and lower limbs (approximately 50\% of predicted), suggesting that both the FAO and non-FAO groups have muscle weakness. Muscle weakness might be explained by the fact that subjects with moderate-to-severe asthma are more sedentary and present a greater number of exacerbations, leading to an increase in the dose of oral corticosteroids needed $(26,35,36)$.

The HRQoL scores were similar between the FAO and non-FAO groups in all the questionnaire domains (physical activity, emotions, and symptoms). Amaral et al. (2014) evaluated HRQoL in adolescents with a lower or normal peak expiratory flow, and the authors did not observe any significant differences between them (37). Our results are supported by those in previous studies demonstrating that adolescents with controlled and partially controlled asthma have a better HRQoL $(38,39)$. In addition, a worse HRQoL in subjects with uncontrolled asthma is associated with fewer symptom-free days (40). Taken together, these results suggest that HRQoL in adolescents is more strongly related to asthma control than is airflow obstruction.

Our study has limitations. First, because the incidence of FAO in adolescents is low, we had to recruit a large number of adolescents for the FAO group; however, the number of adolescents reached the sample size calculation. Second, we did not include a group of adolescents without asthma; however, the most recent systematic review demonstrated no differences in physical fitness between adolescents with and without asthma (25). Finally, adolescents were selected based on their spirometry results, and complete lung function (volumes and capacities) was not evaluated. However, the LLN, assessed by spirometry, has been reported to be a good index for detecting FAO (3).

\section{Conclusion}

Adolescents with asthma and FAO and those without FAO have similar levels of aerobic fitness, physical 
activity, peripheral muscle strength, and quality of life. However, adolescents with FAO have greater expiratory muscle strength. The low exercise capacity and the presence of muscle weakness observed in both groups may have occurred due to the high level of sedentarism.

\section{References}

1. Global Initiative for asthma. GINA report: global strategy for asthma management and prevention. https://ginasthma.org/wp-content/uploads/2019/01/2018-GINA.2018 [

2. Sousa AW, Barros Cabral AL, Arruda Martins M, Carvalho CRF. Risk factors for fixed airflow obstruction in children and adolescents with asthma: 4-Year follow-up. Pediatr Pulmonol. 2020;55(3):591-8.

3. Eschenbacher WL. Defining Airflow Obstruction. Chronic Obstr Pulm Dis. 2016;3(2):515-8.

4. Fehrenbach H, Wagner C, Wegmann M. Airway remodeling in asthma: what really matters. Cell Tissue Res. 2017;367(3):551-69.

5. Zhang L, He L, Gong J, Liu C. Risk Factors Associated with Irreversible Airway Obstruction in Asthma: A Systematic Review and Meta-Analysis. Biomed Res Int. 2016;2016:9868704.

6. Dantas FM, Correia MA, Silva AR, Peixoto DM, Sarinho ES, Rizzo JA. Mothers impose physical activity restrictions on their asthmatic children and adolescents: an analytical cross-sectional study. BMC Public Health. 2014;14:287.

7. Fanelli A, Cabral AL, Neder JA, Martins MA, Carvalho CR. Exercise training on disease control and quality of life in asthmatic children. Med Sci Sports Exerc. 2007;39(9):1474-80.

8. Loponen J, Ilmarinen P, Tuomisto LE, Niemelä O, Tommola M, Nieminen P, et al. Daily physical activity and lung function decline in adult-onset asthma: a 12-year follow-up study. Eur Clin Respir J. 2018;5(1):1533753.

9. Bellocq A, Gaspard W, Couffignal C, Vigan M, Guerder A, Ambard J, et al. Outpatient pulmonary rehabilitation for severe asthma with fixed airway obstruction: Comparison with COPD. J Asthma. 2019;56(12):1325-33.

10. Gordis L. Epidemiology. $2^{\text {nd }}$ ed. Philadelphia, Pennsylvania: W. B. Saunders Company; 2000. 308 p.

11. Pellegrino R, Viegi G, Brusasco V, Crapo RO, Burgos F, Casaburi R, et al. Interpretative strategies for lung function tests. Eur Respir J. 2005;26(5):948-68.

12. Roxo JP, Ponte EV, Ramos DC, Pimentel L, D’Oliveira Júnior A, Cruz AA. [Portuguese-language version of the Asthma Control Test]. J Bras Pneumol. 2010;36(2):159-66.

13. Bray GA. Classification and evaluation of the obesities. Med Clin North Am. 1989;73(1):161-84.

14. Juniper EF, Guyatt GH, Feeny DH, Ferrie PJ, Griffith LE, Townsend M. Measuring quality of life in children with asthma. Qual Life Res. 1996;5(1):35-46.

15. Novaes R, Miranda A, Silva J, Tavares B, Dourado V. Reference equations for predicting of handgrip strength in Brazilian middle-aged and elderly subjects. Fisioterapia e Pesquisa2009. p. 217-22.

16. Black LF, Hyatt RE. Maximal respiratory pressures: normal values and relationship to age and sex. Am Rev Respir Dis. 1969;99(5):696-702.

17. Heinzmann-Filho JP, Donadio MV. [Respiratory muscle strength test: is it realistic in young children?]. Rev Paul Pediatr. 2015;33(3):275-80.

18. Freedson P, Pober D, Janz KF. Calibration of accelerometer output for children. Med Sci Sports Exerc. 2005;37(11 Suppl):S523-30.

19. Borg GA. Psychophysical bases of perceived exertion. Med Sci Sports Exerc. 1982;14(5):377-81. 
20. Rodrigues AN, Perez AJ, Carletti L, Bissoli NS, Abreu GR. Maximum oxygen uptake in adolescents as measured by cardiopulmonary exercise testing: a classification proposal. J Pediatr (Rio J). 2006;82(6):426-30.

21. Almeida AE, Stefani CM, Nascimento JA, Almeida NM, Santos AaC, Ribeiro JP, et al. An equation for the prediction of oxygen consumption in a Brazilian population. Arq Bras Cardiol. 2014;103(4):299-307.

22. Villa F, Castro AP, Pastorino AC, Santarém JM, Martins MA, Jacob CM, et al. Aerobic capacity and skeletal muscle function in children with asthma. Arch Dis Child. 2011;96(6):554-9.

23. Sousa AW, Cabral ALB, Martins MA, Carvalho CRF. Barriers to daily life physical activities for Brazilian children with asthma: a cross-sectional study. J Asthma. 2020;57(6):575-83.

24. Sousa AW, Cabral AL, Martins MA, Carvalho CR. Daily physical activity in asthmatic children with distinct severities. J Asthma. 2014;51(5):493-7.

25. Cassim R, Koplin JJ, Dharmage SC, Senaratna BC, Lodge CJ, Lowe AJ, et al. The difference in amount of physical activity performed by children with and without asthma: A systematic review and meta-analysis. J Asthma. 2016;53(9):882-92.

26. Cordova-Rivera L, Gibson PG, Gardiner PA, McDonald VM. A Systematic Review of Associations of Physical Activity and Sedentary Time with Asthma Outcomes. J Allergy Clin Immunol Pract. 2018;6(6):196881.e2.

27. Zhang W, Wang Q, Liu L, Yang W, Liu H. Effects of physical therapy on lung function in children with asthma: a systematic review and meta-analysis. Pediatr Res. 2020.

28. Santos APD, Strassburger MJ, Roncada C, Stein RT, Pitrez PM, Strassburger SZ. Effect of physical activity on asthma control in schoolchildren. Einstein (Sao Paulo). 2020;18:eAO4936.

29. Ram FS, Robinson SM, Black PN, Picot J. Physical training for asthma. Cochrane Database Syst Rev. 2005(4):CD001116.

30. Oliveira CM, Lanza FeC, Solé D. Respiratory muscle strength in children and adolescents with asthma: similar to that of healthy subjects? J Bras Pneumol. 2012;38(3):308-14.

31. Marcelino AM, da Cunha DA, da Cunha RA, da Silva HJ. Respiratory muscle strength in asthmatic children. Int Arch Otorhinolaryngol. 2012;16(4):492-6.

32. Decramer M. Hyperinflation and respiratory muscle interaction. Eur Respir J. 1997;10(4):934-41.

33. Reimberg MM, Pachi JRS, Scalco RS, Serra AJ, Fernandes L, Politti F, et al. Patients with asthma have reduced functional capacity and sedentary behavior. J Pediatr (Rio J). 2018.

34. Latorre-Román P, Navarro-Martínez AV, Mañas-Bastidas A, García-Pinillos F. Handgrip strength test as a complementary tool in monitoring asthma in daily clinical practice in children. Iran J Allergy Asthma Immunol. 2014;13(6):396-403.

35. Levin OS, Polunina AG, Demyanova MA, Isaev FV. Steroid myopathy in patients with chronic respiratory diseases. J Neurol Sci. 2014;338(1-2):96-101.

36. Cabral AL, Sousa AW, Mendes FA, Carvalho CR. Phenotypes of asthma in low-income children and adolescents: cluster analysis. J Bras Pneumol. 2017;43(1):44-50.

37. Amaral LM, Moratelli L, Palma PV, Leite IC. The quality of life of Brazilian adolescents with asthma: associated clinical and sociodemographic factors. J Asthma. 2014;51(6):660-6.

38. Matsunaga NY, Ribeiro MA, Saad IA, Morcillo AM, Ribeiro JD, Toro AA. Evaluation of quality of life according to asthma control and asthma severity in children and adolescents. J Bras Pneumol. 2015;41(6):5028. 
39. Pereira ED, Cavalcante AG, Pereira EN, Lucas P, Holanda MA. Asthma control and quality of life in patients with moderate or severe asthma. J Bras Pneumol. 2011;37(6):705-11.

40. Hossny E, Caraballo L, Casale T, El-Gamal Y, Rosenwasser L. Severe asthma and quality of life. World Allergy Organ J. 2017;10(1):28.

\section{Hosted file}

Table 1 Pediatr Pulmonol Submission.docx available at https://authorea.com/users/340668/ articles/467696-physical-fitness-and-quality-of-life-in-adolescents-with-asthma-andfixed-airflow-obstruction

\section{Hosted file}

Table 2 Pediatr Pulmonol Submission.docx available at https://authorea.com/users/340668/ articles/467696-physical-fitness-and-quality-of-life-in-adolescents-with-asthma-andfixed-airflow-obstruction

\section{Hosted file}

Table 3 Pediatr Pulmonol Submission.docx available at https://authorea.com/users/340668/ articles/467696-physical-fitness-and-quality-of-life-in-adolescents-with-asthma-andfixed-airflow-obstruction

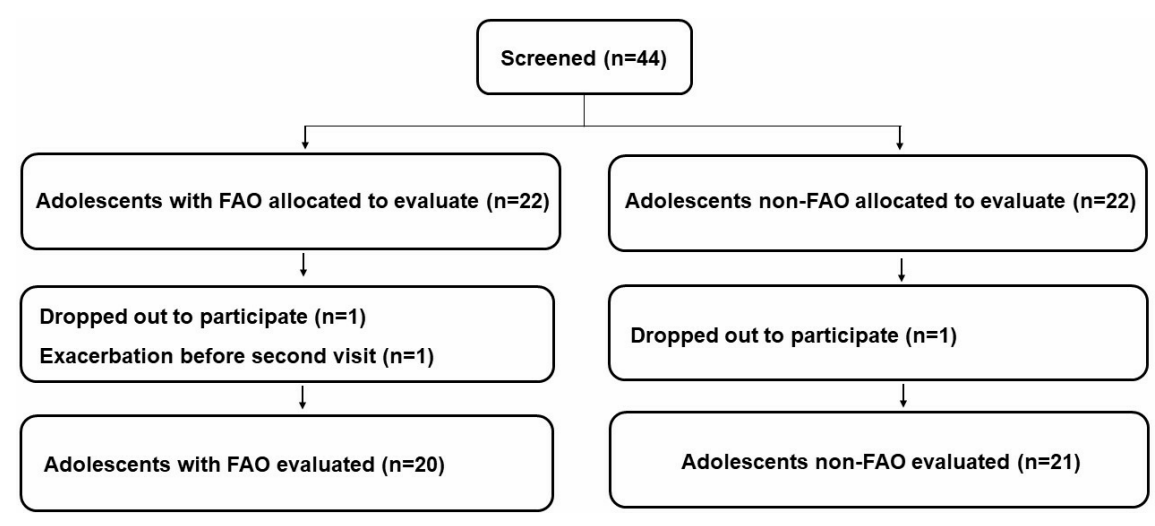

